\title{
An action to an object does not improve its episodic encoding, but
} removes distraction

Laurent, X.; Ensslin, A.; Mari-Beffa, P.

\section{Journal of Experimental Psychology: Human Perception and Performance.}

DOI:

$10.1037 / x h p 0000155$

Published: 01/04/2016

Other version

Cyswllt i'r cyhoeddiad / Link to publication

Dyfyniad o'r fersiwn a gyhoeddwyd / Citation for published version (APA):

Laurent, X., Ensslin, A., \& Mari-Beffa, P. (2016). An action to an object does not improve its episodic encoding, but removes distraction. Journal of Experimental Psychology: Human Perception and Performance., 44(1), 494-507. https://doi.org/10.1037/xhp0000155

Hawliau Cyffredinol / General rights

Copyright and moral rights for the publications made accessible in the public portal are retained by the authors and/or other copyright owners and it is a condition of accessing publications that users recognise and abide by the legal requirements associated with these rights.

- Users may download and print one copy of any publication from the public portal for the purpose of private study or research.

- You may not further distribute the material or use it for any profit-making activity or commercial gain

- You may freely distribute the URL identifying the publication in the public portal ?

Take down policy

'This article may not exactly replicate the final version published in the APA journal. It is not the copy of record.'

Take down policy

If you believe that this document breaches copyright please contact us providing details, and we will remove access to the work immediately and investigate your claim. 


\title{
An action to an object does not improve its episodic encoding, but removes distraction
}

\author{
Xavier Laurent $^{\mathrm{a}}$, Astrid Ensslin ${ }^{\mathrm{b}}$, Paloma Marí-Beffa ${ }^{\mathrm{b}}$ \\ ${ }^{\mathrm{a}}$ University of Oxford, ${ }^{\mathrm{b}}$ University of Bangor
}

\begin{abstract}
There is some debate as to whether responding to objects in our environment improves episodic memory or doesn't impact it. Some authors claim that actively encoding objects improves their representation in episodic memory. Conversely, episodic memory has also been shown to improve in passive conditions, suggesting that the action itself could interfere with the encoding process. This study looks at the impact of attention and action on episodic memory using a novel WWW task that includes information about object identity (What), spatial (Where) and temporal (When) properties. With this approach we studied the episodic memory of two types of object: Target, where attention or an action is defined, and Distractor, object to be ignored, following two selective states: active vs. passive selection. When targets were actively selected, we found no evidence of episodic memory enhancement compared to passive selection; but instead memory from irrelevant sources was suppressed. The pattern was replicated across a 2D static display and a more realistic 3D virtual environment. This selective attention effect on episodic memory was not observed on non-episodic measures, demonstrating a link between attention and the encoding of episodic experiences.
\end{abstract}

Keywords: What-Where-When task; episodic memory; recognition and cue recall; sensorymotor implication; inhibition. 
In our daily experience we often need to avoid responding to objects in an automatic manner in order to pursue a goal. When shopping for groceries, we may find ourselves actively avoiding the cream cakes in order to get the items on the fruit and vegetable list. In a pub, we may need to suppress grasping other glasses on the table to pick our own. In many cases, these situations occur without us being aware of it; but at other times they can become part of our autobiographical experience. While most would agree that selected objects can be stored in episodic memory, it is less clear what happens with the objects that we reject. The purpose of this research is to study how the active selection of a target among distractors is represented in episodic memory.

The most common view is that objects which are the targets of goal-directed actions receive a boost in processing that enhances their representations in episodic memory (Engelkamp \& Zimmer, 1994; Zimmer, et al, 2001). But there is little account of how distractors are represented. Here we present a set of three experiments to demonstrate that, contrary to the previous view, responding to an object does not influence target encoding but acts instead upon distractors, inhibiting them and preventing them from being represented in the episodic trace.

\section{Measures of Episodic Memory}

Before we analyse how distractors can be affected by responses to the targets, we need to clarify a few theoretical points. The first problem that we encounter is the multiplicity of tasks used to measure episodic memory, and even the concept itself. Originally, Endel Tulving (1972) coined the term 'episodic memory' with reference to the very processes used to link the many different types of information constituting an event into a spatio-temporal context. Paradoxically, since this original definition, measures of episodic memory in humans have been more focused on the subjective experience of remembering objects (Cheke \& 
Clayton, 2013), and less exhaustive with respect to the spatial and temporal properties of the memory trace (Tulving, 1982; Magnussen \& Helst, 2007). But when studying episodic memory in populations with low communication abilities, such as children and animals (e.g., Clayton \& Dickinson, 1999), the impossibility of evaluate their "time travel" experience forced researchers to use the so-called 'WWW' task, or 'What, When, Where' method (Clayton \& Russell, 2009). It analyses the three main types of information included in an episodic trace: object identity (What), spatial information (Where), and temporal order (When). This measure is often referred to as "episodic-like" memory test as it does not addresses the phenomenological aspects of the episodic experience (Hampton \& Schwartz, 2004). In the present article we will focus on these non-phenomenological measures.

The term episodic memory itself has often been used to cover a wide range of contextual memory effects. Labels such as source monitoring, event files or autobiographical memories are often used as overlapping but still dispersed fields that have episodic memory in common. However, the real problem arises from the diversity of the tasks they use producing different results. If they all really measured episodic memory then their results should converge, but this doesn't seem to be the case, demonstrating that a "true" measure of episodic memory is yet to be determined (Cheke and Clayton, 2013).

From our point of view, any real test of episodic memory cannot be based on the cumulative retrieval of a number of pieces of information (e.g., I know what porridge tastes like, I know my kitchen, I know the morning has passed), but on their integration (e.g., I've had porridge this morning in my kitchen). If we follow this assumption, then we find a shortage of paradigms directly measuring the integrative nature of the episode. In a typical source memory task, for example, participants are asked to remember different aspects from an episode, such as location, other objects or colours, independently. In addition, these recollections are usually analysed in a rather cumulative way, by counting how many features 
participants can correctly remember (although there are some exceptions, Clayton, Bussey \& Dickinson, 2003; Holland \& Smulders, 2011; Plancher, Nicolas \& Piolino, 2008).

With this cumulative method results cannot be more mixed. When simply counting the number of objects remembered, researchers have repeatedly found that acting on objects during encoding enhances their recognition in general (Attree, Brooks, Rose \& Andrews, 1996; James, Humphrey, Vilis, Corrie, Baddour, \& Goodale, 2001; Harman, Humphrey \& Goodale, 1999). Whether object recognition can be considered episodic or not is a matter of debate (Jacoby, 1991); but the main point is that an enhanced attentional state triggered by their actions seems to improve recognition memory in general. That said, a number of researchers have failed to replicate this effect. Plancher, Gyselinck, Nicolas and Piolino (2007), for example, using a driving simulation context, found no difference between active (drivers) and passive (passengers) participants in both recall and recognition of objects using a virtual environment, finding benefits only on spatial memory. To make the matter worse, in another study from the same team (Plancher, Tirard, Gyselinck, Nicolas \& Piolino, 2012), the collective recall of contextual details even substantially improved during passive compared to active exploration (see also Christou \& Bulthoff, 1999). This lack of target enhancement following an action could possibly be due to the demands of the driving actions interfering with contextual encoding of objects. For example, when driving though a virtual town (see also Christou \& Bulthoff, 1999) participants can be more focused on the complexities of driving than on attending objects. In any case, the diversity of actions and tasks used in these experiments make it very difficult to differentiate effects arising from different attentional states (e.g., intentional encoding vs active exploration). 
Measures of Selective Attention: Distractor Suppression vs. Episodic Mismatch.

As we have seen, a second important problem relates to the manipulation of attention itself. In the previous studies mentioned here, selective attention was inconsistently manipulated, by asking participants to intentionally remember something or actively explore a scene, and comparing performance with a more passive condition. Two distinctive attentional mechanisms seem to be relevant here: a) visual selective attention of objects in complex environments, and b) goal-directed attention. Without a separation of these two aspects it is very difficult to evaluate the role of actions in episodic memory. For example, the level of activity involved when intentionally encoding objects is not clear, because although targets are selectively attended at a perceptual level, we cannot know if they are linked to a response, rehearsed in working memory, or even manipulated with a memorisation strategy. Even more controversial is the analysis of attention in free active exploration contexts, with vast uncertainty and individual variation about the information selected for further encoding at a perceptual or at a response level.

For these reasons, traditional research on mechanisms of attention has been normally achieved in less naturalistic, lab-based, studies using mostly priming tasks. In these studies, an important aspect often neglected in episodic memory literature is that actions to targets are often executed in the presence of distractors. Thus, when the system selects a target object for an action, it often needs to de-select distractor information. A common idea in selective attention studies is that, to fulfil the action distractor objects need to be suppressed in order not to interfere with the task at hand (Tipper, 1985, Houghton \& Tipper, 1994). There is a substantial body of research from the negative priming literature where responses are slowed down when previously ignored distractors appear next as targets. This deterioration in performance has been seen as evidence for the active suppression of distractors during selection. Indeed, many behavioural and neuro-imaging studies have supported the view that 
attention solves ambiguities during target analysis by suppressing irrelevant stimuli to prevent erroneous coding or binding (Mazza, Turatto, \& Caramazza, 2009; see also Awh, Matsukura, \& Serences, 2003).

Although selective attention and episodic memory research are often treated independently, they are functionally linked to each other. Indeed, the theory of distractor inhibition has been traditionally challenged by episodic memory accounts (Neil \& Westberry, 1987; Neill, Valdes, Terry, \& Gorfein, 1992). From their perspective, during selection targets are episodically encoded with their actions and distractors get encoded with a do-not-respond tag. When, in a current episode, the previously ignored distractor appears as a target, there is an episodic mismatch between the current response and the do-not-respond tag that will slow performance. This account has been very successful to explain, for example, those cases in which negative priming have been observed several minutes after distractor presentation, an effect that has been difficult to explain by distractor inhibition models.

A somehow paradoxical aspect of these episodic accounts is that, despite explaining performance in episodic memory terms, they have rarely been tested with episodic memory measures, relying almost exclusively on implicit priming tasks. When measuring episodic memory of targets and distractors we could predict that distractors should be therefore represented in episodic memory. According to the inhibitory account, however, the contents of episodic memory refer to the memory of objects and contextual information that we were aware of during a particular episode. Background irrelevant information might be filtered out without ever being stored in this episodic trace. For example, we may remember what we ate for breakfast this morning, but forget the plate that we used. The plate in this case was not bound to relevant information and therefore was not stored in memory. Therefore, we can assume that only action-relevant objects and other features bound to them are stored in episodic memory. 
From this inhibitory perspective, the role of an action in episodic memory is not to improve encoding as a whole, as previously thought, but by being selective, allowing further encoding only to those objects relevant to the action. If episodic memory is directly related to the results of selective attention mechanisms, then we should observe in episodic memory similar limitations to those studied in selective attention tasks, such as distractor inhibition, limited capacity, and competition between objects or their corresponding actions.

Despite the relevance of analysing distractor processing, studies evaluating how selective attention influences episodic encoding normally measure targets exclusively. A recent example can be found in Rosner, D'Angelo, MacLellan and Milliken (2014) study. Just like us, they aimed to examine the influences of selective attention on episodic memory. To do so, they presented a selective attention task where a target had to be selected against either a congruent distractor (target and distractor were associated to the same response) or an incongruent one (the responses to target and distractors were different). Later, in a recognition test, participants were shown a number of items to respond if they had seen them before or not. Importantly, despite the interest on episodic learning, episodic memory was never tested. Indeed, participants were never asked about any contextual elements such as space or time. But even more important, the researchers only collected recognition memory from the target and never from the distractors. The authors found a boost on recognition memory for targets only in the incongruent condition, concluding that there is a link between cognitive control (via selective attention) and episodic memory. Still, their results could also be explained in a different way. In the congruent condition items to attend and ignore were identical, and it is a well-established phenomenon that selection between identical or related item can lead to interference created by uncertainty of what to attend (MacLeod, 1991). If we only measure the targets, then we could expect better memory for target on incongruent trials, where target identification becomes easier. According to this interpretation they did not find target 
enhancement for incongruent items but target reduction for congruent ones. Without testing memory from the distractors (difficult in the congruent condition) it is impossible to draw any conclusions about how episodic memory changes in the different congruency conditions.

\section{Binding of Target and Distractor Properties in an Episodic Trace}

A possibly more direct link between attention and episodic memory can be taken from recent work by Moeller and Frings (2014). Here the authors wondered whether the binding of responses to targets as part of their event files also reach distractors. Their idea is somehow different to the attentional inhibition of distractors defended by Tipper and colleagues (Houghton \& Tipper, 1994). According to their view, attention to one part of the scene may open the gate to process other parts of it, similar to what occurs when attention to one part of an object induces the processing of the whole object (Baylis \& Driver, 1992). When responding to a target in a scene, co-occurring distractors can also be integrated with responses, being later retrieved when this response is required (the distractor-response binding effect, Frings, 2011, Frings \& Moeller, 2010). The important aspect for this binding is that it only affects perceptually attended (but not responded to) distractors. When distractors are not attended, they do not elicit the response binding effect. Unfortunately, as the authors acknowledge, their results cannot be readily interpreted in episodic memory terms as they use priming tasks where implicit manifestations of encoding processes are tested with delays of only a few hundred milliseconds (see also Neil \& Westberry, 1987). Nevertheless, their results are relevant for our purposes, as they show that attention is crucial to binding different properties of an event, including responses, in an integrated representation.

A common aspect in these two studies (Rosner et al., 2014; Moeller \& Frings, 2014, see also Hommel, 2010) is the introduction of action systems (or responses) as critical in the formation of episodic (or event) representations. Indeed, the level of cognitive control 
required during an action might be the trigger of an enhanced selective attention state that binds properties in a memory trace. Non-competing distractors could be attended and encoded as part for the event itself. As mentioned earlier, most of these selective attention studies use implicit means of testing, so these conclusions need to be considered with caution when extrapolated to explicit episodic memory tasks. Indeed, attentional states that had no effect on an explicit retrieval test were found to modulate implicitly tested retrieval processes (Boronat \& Logan, 1997; Logan \& Etherton, 1994; Logan et al., 1999). Since processing seems to differ between intentional and unintentional retrieval, it is quite possible that these processes are influenced differently by attention.

The next step is to demonstrate that this initial attentional processing is further bound to an episodic memory trace that can be explicitly retrieved after several minutes. Therefore, in the present study, we will take explicit measures of episodic memory for targets and distractors following two kinds of selective attention states: one in which the target is only perceptually selected in order to be later remembered in an episodic memory test; and a second condition in which the target needs to be selected by responding to it.

\section{Current Research}

As we mentioned earlier, our aim is to use a variation of the WWW task to comply with a number of objectives. The most important one is that we can use it to study the binding of contextual features to objects. In a first test we studied the original features as defined by Tulving (1972)'s original definition of episodic memory; but with the idea that the test could be extended to test other contextual features, including associated responses, although this has not be tested here. Binding, in this context, is understood in statistical terms, by analysing participant answers against chance. Indeed, the chances of getting all three aspects of an episode correct are usually low, but measurable, so we corrected all responses accordingly. In 
some instances, however, we find that some aspects have been successfully bound to the object whilst others haven't (for example, the location of a particular object might be correct, but not the time). In these cases we consider these memories as non-episodic and analyse them separately. Here we should note that this is a very conservative approach, as it could be argued that partial bindings can also be considered episodic. Finally, completely non-episodic memory estimation comes from those responses in which participants correctly remember the object, but fail to report its location and time.

In conclusion, the role of actions in the encoding of episodic memory is an aspect that has only scarcely been studied in memory research, producing mixed results. There is little agreement on which procedure should be used to study episodic memory, or which aspects of it should be considered episodic. To this multiplicity of tests and theoretical definitions, we need to add further complexity as to what an action means. Indeed, an active mode of encoding could be inferred because a participant is simply asked to memorize objects and their locations (Van Asselen, Van der Lubbe \& Postma, 2006), or else it may refer to the full bodily involvement of the participant in an actual experience (Holland \& Smulders, 2011).

In this study, we developed a WWW paradigm for adults to study how these three different kinds of representations, objects, locations and time, are encoded episodically and non-episodically as well as how the actions that we perform have an influence on the type of information stored in these episodic traces. To analyse the influence of active vs. passive encoding on episodic memory, we tested two different conditions: a) active mode, where participants need to produce a motor response to a target while ignoring distractors, and b) passive mode, where participants are asked to observe scenes where the same target objects are externally cued. We used a version of the WWW task to test memory for the object identity (What), spatial (Where) and temporal component (When) both separately (nonepisodic) and bound together (episodic memory). 


\section{EXPERIMENT 1}

In this study we use a cue-recall task to induce episodic retrieval in a WWW task ${ }^{1}$. The names of different objects, targets, distractors or new objects, were presented, as cues and participants needed to answer needed to answer whether or not the presented cues were amongst the targets for the task.

\section{Participants}

Total sample size was estimated a priori using $\mathrm{G}^{*}$ Power 3.1.9.2 (Heinrich Heine University Düsseldorf, Germany). With $\alpha$ set to 0.05 and a desired power of 0.90 or above for the $2 \times 2$ mixed ANOVA interaction we expected to obtain an effect size of 0.25 and repeated measures correlations of 0.5 (as previously observed in pilot testing), producing a minimum required sample size of 46, with 23 participants in each group. 46 (30 females, 16 males) participants were therefore recruited to take part in this study. 23 of them were assigned to the active mode group ( 15 females and 8 males) and 23 to the passive mode (15 females and 8 males). All participants were recruited from a university participant recruitment system and received course credits for their participation. They ranged in age from 19 to 45 years $(\mathrm{M}=$ $25, \mathrm{SD}=8.8$ ). None of the participants reported having any memory deficit or other cognitive dysfunction. They all reported to have normal or corrected-to-normal vision. Bangor University's School of Psychology's internal ethics committee approved the study.

\section{Apparatus \& Stimuli}

The objects used for the memory task were all drawn from a string of standardised pictures from the Snodgrass and Vanderwart database (Snodgrass \& Vanderwart, 1980).

\footnotetext{
${ }^{1}$ We previously piloted a free recall version of the task, which was meant to tap episodic memory processes more strongly than cue-recall (e.g., Perner \& Ruffman, 1995). Although the pattern of results was identical to the one observed here, the accuracy rate was nevertheless extremely low. We therefore tested other retrieval techniques such as cue-recall reported here. The potential differences across procedures will be discussed in the general discussion.
} 
From the 256 objects in the database we selected the 32 with highest percentage of name agreement, $95 \%$ to $100 \%$. An initial set of 16 original target/distractor objects was presented to participants during encoding ("old" objects). An additional 16 new random objects taken from the same database were mixed with the previous ones as fillers during the recognition phase ("new" objects). The stimuli for this task were presented using a laptop computer with a 15 " monitor running at a resolution of 1024 X 768 pixels for viewing from about $60 \mathrm{~cm}$.On average, the visual angle for each object was 2.2 degrees. Stimuli were selected randomly from the dataset for each participant. They all appeared on a static screen with a white background divided into 4 squares with 2 objects appearing in different blocks and in random positions each time (see Figure 1). A green asterisk cued the target object.

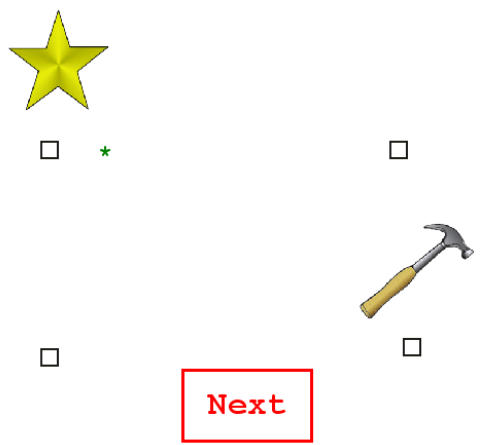

Figure 1. Sample of encoding stimulus trial.

\section{Procedure}

The two groups of participants were randomly assigned to each of the two modes: passive and active. Both mode displays were identical, and the only difference was the task that participants had to perform. In the passive mode, the target was the object with a green asterisk next to it, which participants needed to focus on during the 5 seconds before the next slide appeared automatically. In the active mode, participants had to click on the target object (marked with the green asterisk) in order to move to the next slide. 
For the cue recall phase the participants were presented with a screen showing the name of the objects (distractor, target and new) at the top with a tick box next to it (see Figure 2). From the "what" task, participants were asked if they remembered the object by presenting the name of the object as a cue and, if they did not, they were then asked to click on the next button to move onto the next slide. However, if they believed that they remembered the object, then they were asked to click the tick box, and were subsequently asked to answer the "where" and "when" forced choice questions.

check the box if you have seen this object

\section{STAR}

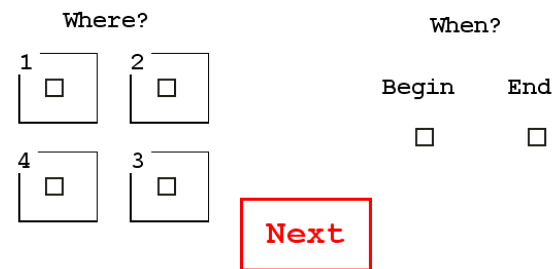

Figure 2. Sample of a cue-recall test screen for the different elements of episodic memory.

The memory task took place immediately after all the stimuli were presented. The duration of the total task, including the recall phase, was an average of 10 minutes. See Figure 3 for an example of stimuli sequence.

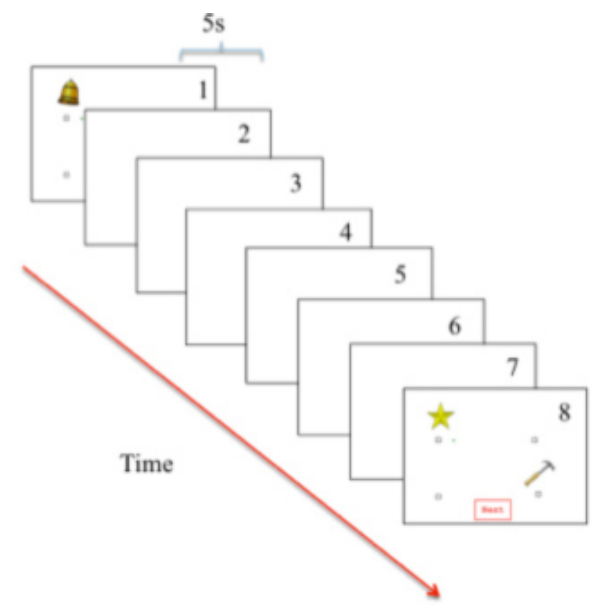

Figure 3. Sequence of stimuli during the encoding phase 
A Conservative approach was used in which episodic retrieval of a particular object was inferred only in those cases where the three memory components, 'What', 'Where' and 'When', were correct (full episodic recall measure). Significant recall was estimated against the chance ${ }^{2}$ level of $0.0625^{3}$. Positive recognitions of objects that were not presented either as target or distractor were computed as false alarms (see Table 1). However, partially recalled objects were also measured for object identity, spatial location and temporal position. We analysed these as three non-episodic measures of object recognition: "What" means that the object was correctly identified, but they failed to report where and when it appeared (chance level at $0.1875^{4}$ ); "Where" means that both object and location were correctly identified, but they failed to report when it appeared (chance level at $0.0625^{5}$ ); and "When" means that both object and time where correctly reported, but the location was incorrect (chance level at 0.1875). None of these non-episodic objects are contained in the full EM measure.

\footnotetext{
${ }^{2}$ We adjusted the values to save the reader from the burden to calculate these adjustments every time they see a new graph, for example memory for objects if 50\% (yes or no) and produce false alarms therefore value for objects will be higher for the spatial location (4 components).

${ }^{3} 0.0625$ is the probability of correctly guessing the three properties: What, 0.5 ; Where, 0.25 ; When, 0.5 .

${ }^{4} 0.1875$ is the probability of correctly guessing the object $(0.5)$ while getting both the space and time incorrect ( 0.75 and 0.5 respectively)

${ }^{5} 0.0625$ is the probability of correctly guessing the object ( 0.5$)$ and the location $(0.25)$, but randomly getting the time wrong $(0.5)$.
} 


\section{Results}

Data for one male participant in the passive mode were removed due to technical error. Means of overall accuracy rates from the resulting 45 participants were analysed through a 2 (Objects: Target, Distractor) x 2 (Modes: Passive, Active) mixed Factorial ANOVA where Objects were manipulated within subject and the Mode was manipulated between groups.

Table 1. Distribution of overall percentage of trials in each of the memory categories across experiments. Old items were those presented during the study phase. New items were fillers used only during the test phase.

\begin{tabular}{lccccccc}
\hline & & \multicolumn{2}{c}{ Experiment 1 } & \multicolumn{2}{c}{ Experiment 2 } & \multicolumn{2}{c}{ Experiment 3 } \\
\hline & Memory & Active & Passive & Active & Passive & Active & Passive \\
\hline Old items & Episodic & 28 & 34 & 38 & 46 & 26 & 38 \\
& What & 8 & 12 & 10 & 06 & 8 & 08 \\
& What-Where & 10 & 12 & 10 & 16 & 14 & 12 \\
& What-When & 16 & 24 & 18 & 18 & 2 & 2 \\
& Errors & 38 & 18 & 24 & 14 & 32 & 22 \\
\hline New items & False Alarms & 4 & 6 & 4 & 4 & 6 & 4 \\
& Correct rejections & 96 & 94 & 96 & 96 & 94 & 96 \\
\hline
\end{tabular}

Note: Specific separation of trials for Target and Distractor objects are depicted in the figures for each experiment

Full episodic recall (What, Where and When correct)

In the full episodic recall test there was a reliable two-way interaction $[F(1,43)=5.4$, $\left.p=.025, \eta_{\mathrm{p}}^{2}=.13\right]$ showing that, for the active mode, distractors were recognised significantly less often than targets $(t(22)=4.3, p<.001)$; but there were no differences in the passive mode $(p=0.9)$. Additionally, we also found that memory from distractors was 
significantly reduced in the active mode compared to the passive mode $(t(43)=2.51, p=$ .016) while target memory was not enhanced in the active mode compared to the passive one. Indeed, the action did not improve memory for targets, but reduced the memory of distractors, which we interpreted as evidence for distractor suppression. No other effects reached significance.

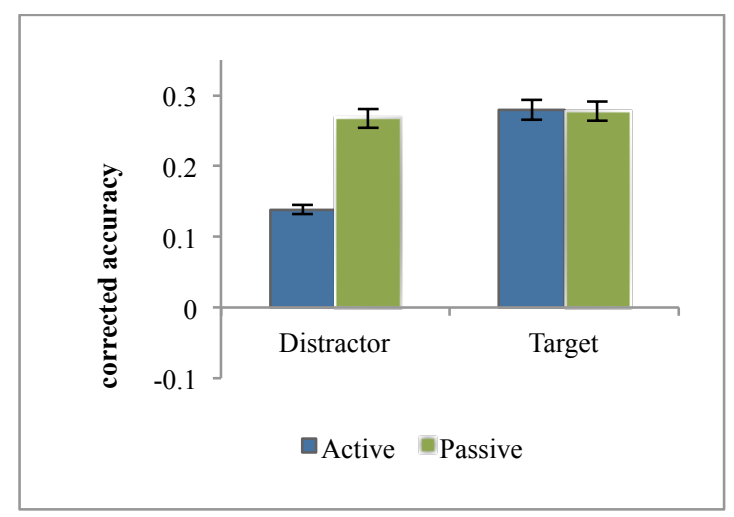

Figure 4. Mean accuracy values corrected by chance (0.0625) for full episodic memory. What (Non Episodic Object Recall)

In the 'what' test we only analysed data from successfully remembered objects with no recollection of where and when they appeared. This time none of the measures were significantly different from chance.

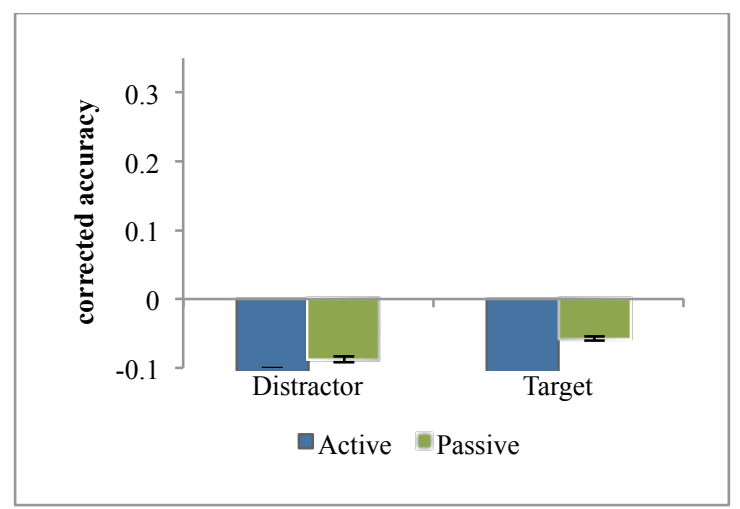

Figure 5. Mean accuracy values corrected by chance (0.1875) for non-episodic object cue recall. 
In the 'where' test there was a marginally significant two-way interaction between Mode and Objects $\left[F(1,43)=4.5, p=.04, \eta_{\mathrm{p}}^{2}=.1\right]$. Memory from distractors was significantly reduced in the active mode compared to the passive mode $(t(43)=2, p=.05)$. No significant other interactions were present, with memory for all objects except active target rising above chance $(\mathrm{p}=.003)$ and memory for passive distractor $(\mathrm{p}=.009)$.

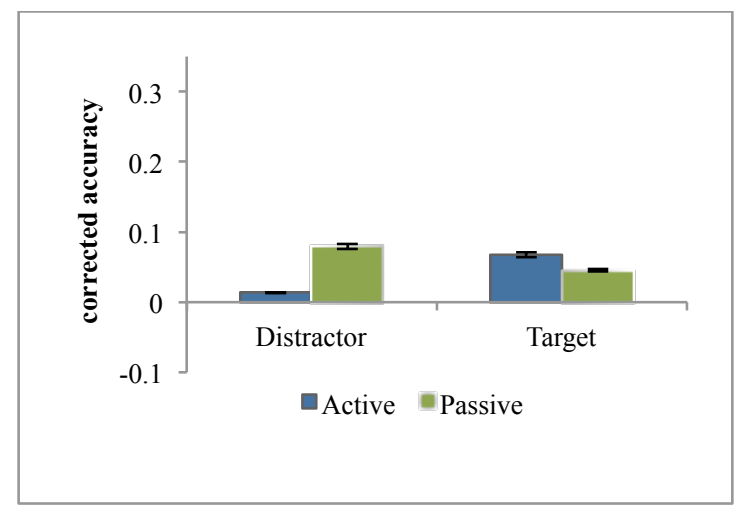

Figure 5. Mean accuracy values corrected by chance (0.0625) for non-episodic spatial recall. Here we include accurate recognition of the object and location with no recollection of when it appeared.

When (Recognition of Objects with their Time, but not Location)

In the 'When' test there was no reliable two-way interaction between Mode and Objects. None of the measures were significantly different from chance. 


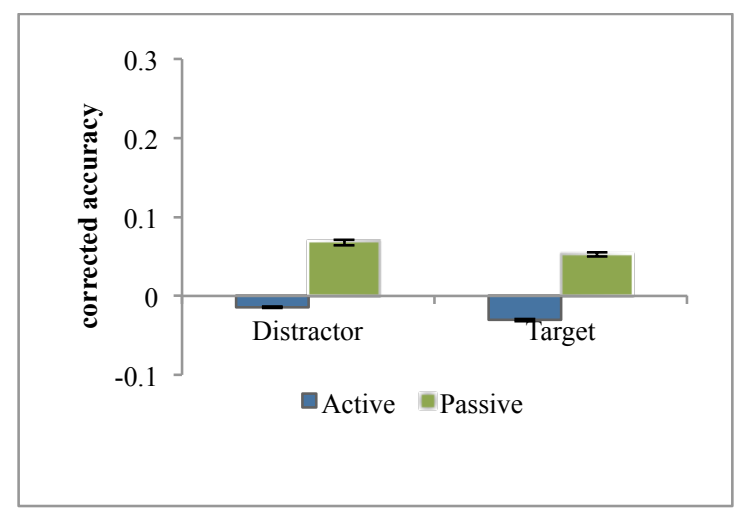

Figure 6. Mean accuracy values corrected by chance (0.1875) for non-episodic temporal recall. These data include accurate recognition of the object and temporal location with no recollection of where it appeared.

\section{Discussion}

The new paradigm task (What-Where-When task) has been effective in producing a very specific pattern of episodic memory recall that can be dissociated from other nonepisodic measures. It can be observed that for episodic memory, when participants actively select a target, it produces a reduction on the memory of distractors, demonstrating the influence of selective attention upon episodic encoding. There are two ways in which we could interpret these results: 1) the target receives enhanced attention and therefore it is better encoded or 2) the distractor is suppressed (inhibited) following the selection of the target, so its memory is impaired. However when comparing active and passive conditions, there is no difference in memory for targets, demonstrating that the action does not enhance target processing (Rosner et al, 2014). Instead, distractors in the active condition are less accurately remembered than in the passive one, supporting the inhibitory account (Houghton \& Tipper, 1994).

Our measure of episodic memory is highly conservative as it contains information only about objects that have been successfully bound to both their spatial and temporal properties. Partial bindings to only one of them (the Where and When measures) were 
analysed separately because there could be some doubts as to whether these partial binding conditions can be considered as episodic or not. A more distinctively non-episodic memory measure can be found with the 'What' measure, in which participants remembered the object, but could not remember where or when they saw it. Importantly, in this category we found no memory of any type of objects, becoming more relevant in the case of the active condition, where we could have expected a memory increase. These results are also partially confirmed when looking at the Where and When non-episodic measures, in which the active condition leads to a minimum recall. This pattern of results reveals that most of the memories taking place in the active condition are episodic in nature, clearly favouring target against distractor objects.

However, despite the lack of significant interactions between the active modes (active/passive) and the type of object (target/distractor), we can still observe that, especially in the Where non-episodic measure, there is a trend for selective distractor suppression in the active condition with no change for the target. Part of our argument earlier was that distractor suppression only manifests in episodic memories, so this result may seem to contradict our ideas. It is possible that this pattern did not reach significance because of the low accuracy rates in this task, with no condition reaching higher than $30 \%$ of the presented objects. For the next experiment we sought further replication in a recognition task for the objects (still cue recall for space and location), which has traditionally produced superior memory retrievals (Roediger, 1973). 


\section{EXPERIMENT 2}

This experiment was identical to Experiment 1, but the memory test, instead of being cued by a word, it was cued by the object itself to improve memory rates.

\section{Method}

\section{Participants}

A total of 50 (32 females, 18 males) participants took part in the study; 27 (16 females, 11 males) of them in the active mode group and 23 (16 females, 7 males) to the passive mode one. They ranged in age from 18 to 42 years $(M=24, S D=7.1)$. Recruitment, ethics and methodological procedures were following those in Experiment 1. None of the participants reported having any visual, memory or other cognitive dysfunction.

\section{Apparatus \& Stimuli}

All stimuli were identical to those used in Experiment 1 except that, instead of words, we used images of objects as cues during the memory test.

\section{Procedure}

For the recall phase, the participants were presented with a screen showing the objects (distractor, target and new) at the top with a tick box next to it (Figure 7). The rest of the procedure was identical to Experiment 1. 


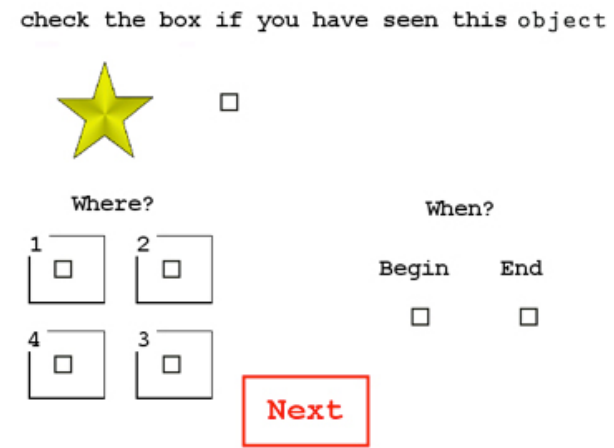

Figure 7. Sample of a memory task item (what recognition).

\section{Results}

Data from one female participant in the passive group were lost due to technical error. Means of overall accuracy rates from 49 participants were analysed through a 2 (Objects: Target, Distractor) x 2 (Modes: Passive, Active) mixed Factorial ANOVA where Objects were manipulated within subject and the Mode was manipulated between groups.

\section{Full episodic recall (What, Where and When correct)}

In the full episodic test as expected, distractor objects were remembered less than target objects $\left[F(1,47)=14.7, p<.001, \eta_{p}^{2}=.24\right]$. But this difference was greater for the active mode than for the passive one $\left[F(1,47)=11.7, p<.001, \eta_{\mathrm{p}}^{2}=.20\right]$. Indeed, targets were remembered an overall of $33.8 \%$ better than distractors $(29 \%)$ in the passive mode; but this difference was up to $35.6 \%$ in the active mode $(t(26)=7.02, p=.001)$.

More importantly, there was a reliable two way interaction $[F(1,47)=14.73, p<.001$, $\left.\eta_{p}^{2}=.24\right]$. This interaction shows that for the active mode distractors were recognised significantly less often than targets $(t(26)=5.7, p<.001)$, but this selection pattern did not emerge in the passive mode $(p=1)$. 
Additionally, we also found that memory from distractors was significantly reduced in the active mode compared to the passive mode $(t(47)=2.81, p=.007)$, while target memory was not enhanced in the active mode compared to the passive one. Indeed, the action did not improve memory for targets, but reduced the memory of distractors, which we interpreted as evidence for distractor suppression.

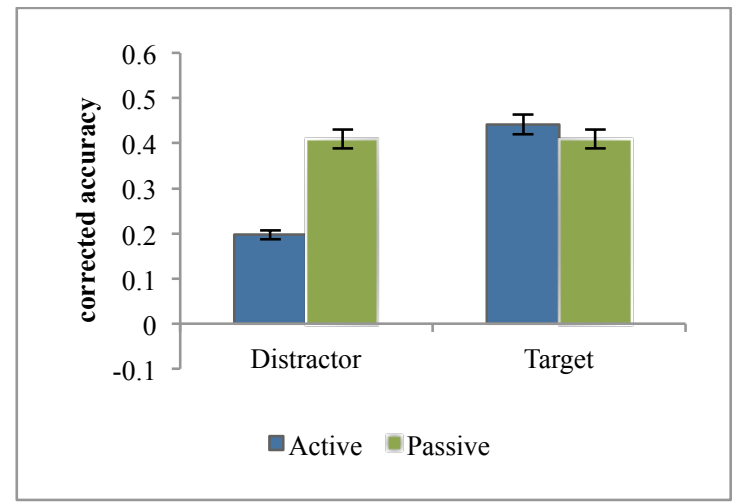

Figure 8. Mean accuracy values corrected by chance (0.0625) for full episodic memory.

What (Non Episodic Object Recall)

In this test of non-episodic recognition, no measures raised above chance levels.

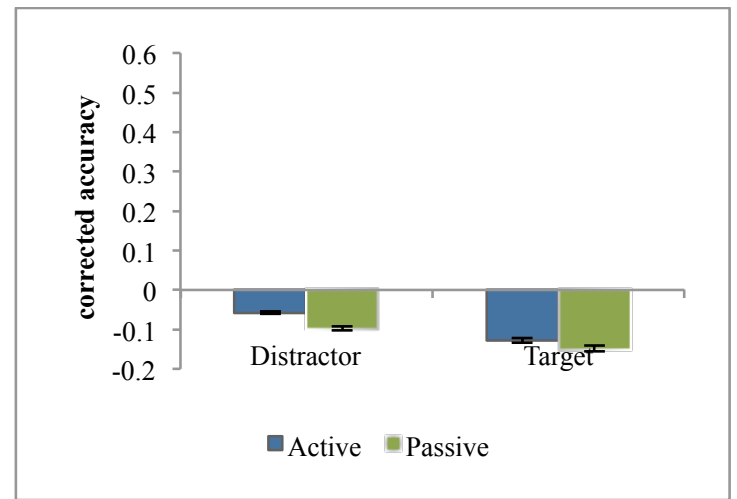

Figure 9. Mean accuracy values corrected by chance (0.1875) for non-episodic object identity recall. Here we include accurate recognition of the object with no recollection of where and when it appeared. 
Where (Non Episodic Recognition of Objects and their Spatial Location)

The recall of objects changed depending on the mode $\left[F(1,47)=5.41, p=.02, \eta_{\mathrm{p}}^{2}=.1\right]$. The targets were remembered better than the distractor in the passive one $(t(21)=3.05, p=$ .006). Memory for targets was better in the passive mode than in the active one, $(t(47)=2.0, p$ $=.05)$. When tested against chance, only the targets in the passive one where significantly better than zero.

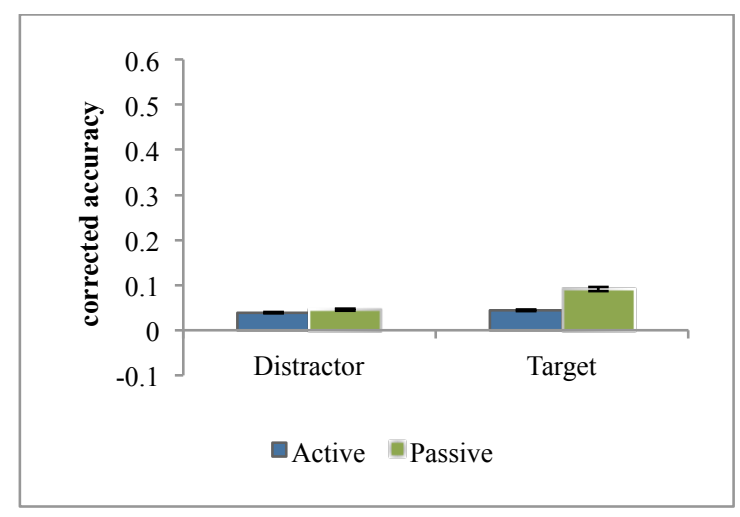

Figure 10. Mean accuracy values corrected by chance (0.0625) for non-episodic spatial recall. Here we include accurate recognition of the object and location with no recollection of when it appeared. 
There was no memory different from chance for any of the conditions in the 'When' test.

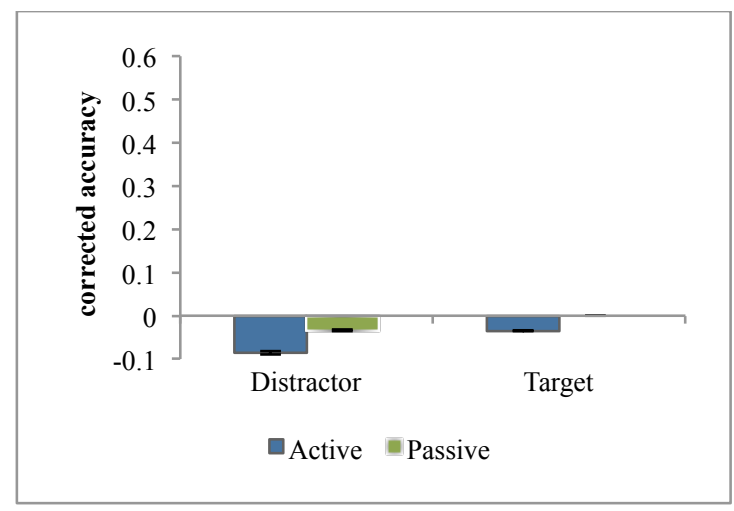

Figure 11. Mean accuracy values corrected by chance (0.1875) for non-episodic temporal recognition. These data include accurate recognition of the object and temporal location with no recollection of where it appeared.

\section{Discussion}

In this second experiment we replicated the main results found in Experiment 1 where we observed distractor suppression without target enhancement during the full episodic recall condition. Importantly, the results in this second experiment further confirmed that successful partial bindings of objects to either their spatial $(11 \%)$ or the temporal properties $(2.5 \%)$ in isolation are minimal compared to the successful binding of the three properties together (35\%), suggesting that space and time are preferably co-encoded in what we consider an episodic trace.

Also, even after having successfully increased overall memory rates by using a recognition task, non-episodic memory of objects (the What component) was absent. It has been long debated whether it is possible to separate the relative contribution of implicit and explicit sources of memory in different tasks (Jacoby, 1991). In our case it could be argued that the use of a recognition task can contaminate episodic measures with less-episodic 
implicit information. We found this highly unlikely in the WWW paradigm presented here. Firstly, our procedure (see also Holland \& Smulders, 2011, for a similar approach) allows the dissociation between episodic and non-episodic measures of memory and thus estimate the relative contribution of the recognition task on each type of measure. Therefore, any contamination should have been expected to raise memory in non-episodic measures, but we only found and increase in the episodic one. But even more importantly, any true measure of episodic memory should be consistent across tasks (Cheke \& Clayton, 2013) and the pattern of distractor suppression in the active condition has been very consistent across the cue-recall and recognition tasks used here (also generalising to free recall, see Footnote 1). This further demonstrates that distractor inhibition is a true property of episodic memory and that it has not been induced by implicit information filtered in by the recognition task.

In the next experiment we sought further replication while extending our paradigm to a completely new environment. 


\section{EXPERIMENT 3}

Our aim was to replicate the last experiment inside the virtual 3D environment Second Life (Linden Lab 2003). A key point relevant to psychology research is that virtual environments allow the study of cognitive functions under more ecological conditions than standard 2D experiments such as E-prime. For example, Second Life has been used in social psychology and cognitive science research, where researchers can build facilities comparable to a real-world laboratory conditions (Kraeme, 2013; Toro-Troconis \& Kamel Boulos, 2009, see also World of Warcraft (Blizzard Entertainment 2014), which has been used in research about social networks and economic systems (Bainbridge, 2007).

The active mode in this experiment required the participants to interact with the virtual environment during the encoding phase; their actions where then recorded and used for the passive mode. An important point to mention here is that the purpose of this experiment was to seek replication of previous results in a completely new environment, rather than to compare $2 \mathrm{D}$ vs. $3 \mathrm{D}$ contexts as they differ in far too many variables. In our lab we tested seven experiments with different methodological variations not included here as they all produced the same pattern of results in the episodic condition. The choice of this version with Second Life was chosen as it demonstrates the validity of our effects by generalizing it to a whole new set of conditions. 


\section{Method}

\section{Participants}

Because of methodological differences between this and previous two experiments, new estimations of sample sizes were calculated following previous pilot data showing repeated measures correlations of 0.55 and similar parameters of power, alpha and effect size. These new estimations produced a desired sample size of 40 or higher in total, 20 participants per group. In this study 41 participants took part: 20 in the active mode (15 females and 5 males) and 21 in the passive mode (14 females and 7 males). Recruitment was identical to previous experiment, but this time they received $£ 5$ each for their participation. They ranged in age from 18 to 43 years $(M=24, S D=6.6)$. None of the participants reported having any visual, memory or cognitive dysfunction.

\section{Apparatus \& Stimuli}

All 3D objects used in this study were either created using the 3D interface in Second Life (SL), chosen from a pre-existing gallery inside Second Life, or bought online in various online shops (e.g. https://marketplace.secondlife.com). No other external tools were used to enhance the look and feel of the objects, and no shading or texture was added to the prims ${ }^{6}$ with $S L$ tools. Objects were made of one prim only or a sculpted prim. The experiments ran inside $S L$ 's Bangor University Island in a free development space (a sandbox). The only visual details apart from the objects were blue sky, and a partial view of the sea and the floor where the avatar was moving around the scene (see Figure 12).

\footnotetext{
${ }^{6}$ In Second Life, virtual physical objects such as cars, houses, jewellery, and even less obvious things like hair and clothing are made out of one or more prims, or basic 3D geometric building blocks. Objects made from prims are usually created in the world using the built-in object-editing tool. The advantage of using primitives is their simplicity. $S L$ is web-based, and everything the user sees needs to be rendered on their machine.
} 


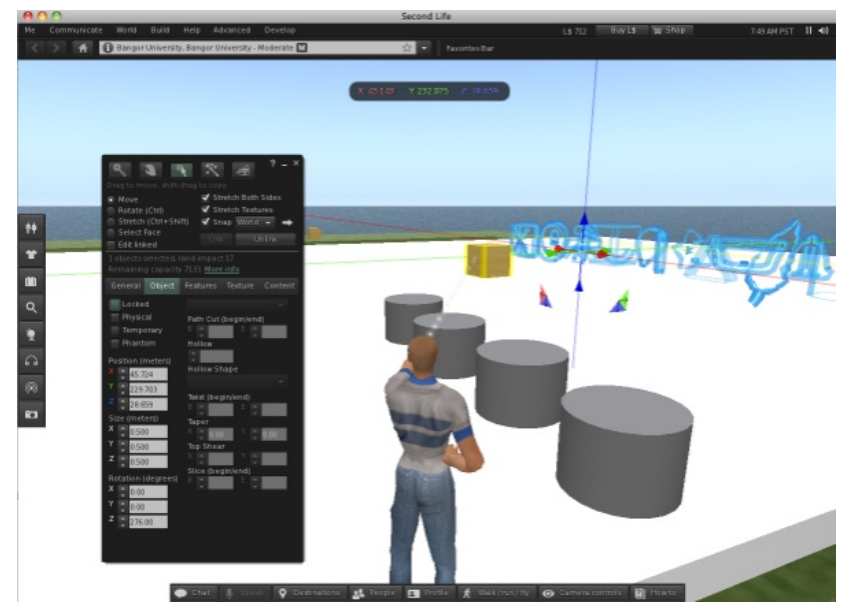

Figure 12. Content creation and set up of the experiment in Second Life.

The stimuli were presented using Second Life on a Mac Book Pro laptop with a 15" monitor. Viewing distance was approximately $60 \mathrm{~cm}$; the visual angle for each object was 2.2 degrees. Manipulation of the avatar in Second Life was operated using a standard QWERTY keyboard (track pad to point at objects + arrow keys to move the avatar in the virtual environment).

The four cylinders were used to mark the spatial location of objects (Figure 13). The cylinders were equally spaced to avoid chunking during encoding, and thus avoid learning strategy by increasing short-term memory (Miller, 1956).

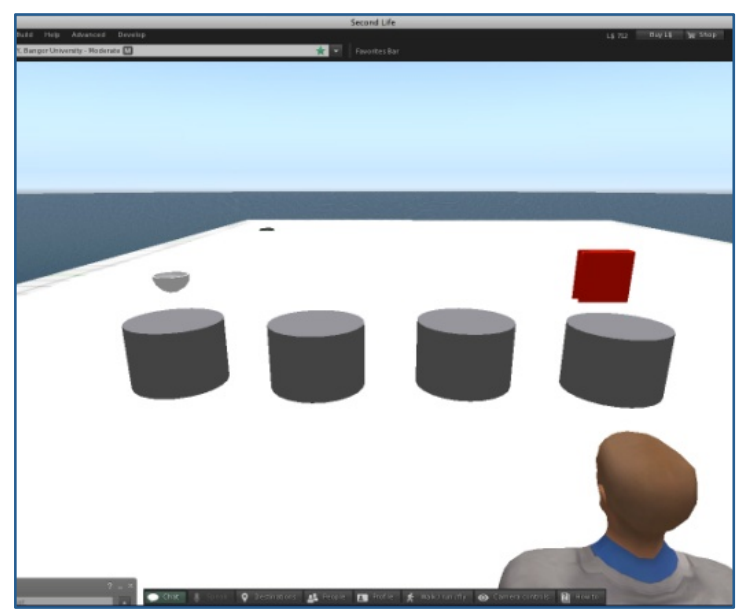

Figure 13. Second Life as seen by participants. 


\section{Procedure}

Similarly, there were two groups of participants randomly assigned to each of the two modes: passive and active. Both mode displays were identical, and the only difference was the task that participants had to perform. In the active mode, participants had to navigate the avatar in Second Life and start the task by clicking on a square box. A pair of random objects would then appear in random locations above cylinders (one distractor in white and one flashing target in red). The avatar had to point to the flashing target object in order to move to the next pair of objects. Should the participant not click on the target object immediately, after 10 seconds a new pair of random objects would appear. In the passive mode, participants were subjected to the same stimuli as the active participants. The stimuli were recorded as a movie using Camtasia (TechSmith Corporation, 2011) during the active mode while active participants were doing their own task. At the end of the sequence, the square box came back to its original position. Every passive participant watched a different video from the active participant experiment.

The avatar was always represented in the $3^{\text {rd }}$ person perspective. Some scripting had to be done to enable the functionality of objects appearing in specific locations. As in the other experiments, there was a set of 16 objects to remember ( 8 distractors and 8 targets) and 16 new objects. The total time of the experiment lasted on average 20 minutes $^{7}$. Active participants were first introduced to Second Life and had a practice run before the real test. Similarly passive participants were also presented a sample video before taking the encoding task and went through the same procedure as the active participants.

After the memory tasks, the participants were directed to a SurveyMonkey web page where they completed an online questionnaire for the memory tasks. The questionnaire

\footnotetext{
${ }^{7}$ Participants took the same amount of time to encode in the passive and active modes compared to Experiment 1 and 2 ( $3 \mathrm{~s}$ in the active and $5 \mathrm{~s}$ in the passive mode). However this difference of time does not affect the results we obtain in this experiment.
} 
included the "What" cue task indicating the objects' names. Included in the questionnaire were random objects (false alarms) during the delayed recall task. Participants were asked if they remembered the object and, if they did not, they were then asked to click on the next button to move onto the next set of question. However, if they believed that they remembered the object, they were asked to click the tick box, and were consequently obliged to answer the "Where" and "When" question (forced choice). The "Where" cue-recall task simply required the participants to indicate above on which cylinder they had seen the object. The "When" cue-recall task was prompted by a "begin" and "end" tick box, where the participants would tick "begin" if they thought that they had seen the object at the beginning of the sequence, and "end" if they thought they had seen the object during the last section of the sequence. The participants were told orally before the start of the task that the beginning of the sequence was the first four pairs of objects and the end of the sequence was the last four pairs. Before the start of the task, the full procedure was explained in detail, in order to avoid participants devising a strategy during encoding.

The same approach was used as for the other experiments, in which episodic retrieval of a particular object was inferred only in those cases where the three memory components (What, Where and When) were correct. However, partial recalled objects were computed for object identity (What), spatial location (Where) and temporal (When).

\section{Results}

Data from 3 participants were removed as their accuracy level for recall fell in the area of more than 3 times the interquartile range (IQR). The data resulting from the remaining 37 participants (18 in the active group, 19 in the passive group) were analysed through a 2 (Objects: Target, Distractor) x 2 (Modes: Passive, Active) mixed Factorial ANOVA where Objects were manipulated within subject and the Mode was manipulated between groups. Note that participants in the passive mode watched videos of those participants in the active 
mode condition as they performed the task. Because of this, participants from both groups were paired. We tested for any correlation in any of the measures across these pairs and found that their performance was largely independent, resulting in the Mode variable being treated as a between group factor as in previous experiments.

\section{Full episodic recall}

Overall target objects were recalled better than distractor objects, $[F(1,35)=6.8, p=$ $\left..013, \eta_{\mathrm{p}}^{2}=.16\right]$, although this difference changed depending on the mode $[F(1,35)=3.8, \mathrm{p}=$ $\left..06, \eta_{\mathrm{p}}^{2}=.1\right]$. Indeed, evidence for targets selected against distractors were observed almost exclusively in the active condition $[t(17)=3.44, p=.003]$, but this selection completely disappeared in the passive mode $(p=.6)$. Importantly, this difference cannot be interpreted as increased memory for the target information, as actively encoded targets were not remembered any better than the more passive ones $(p=.85)$. If anything, overall scores for targets were slightly lower in the active mode. The entire difference arose from the distractor information, where passive distractors were significantly better encoded than the active ones $[t(35)=2.12, p=.04]$.

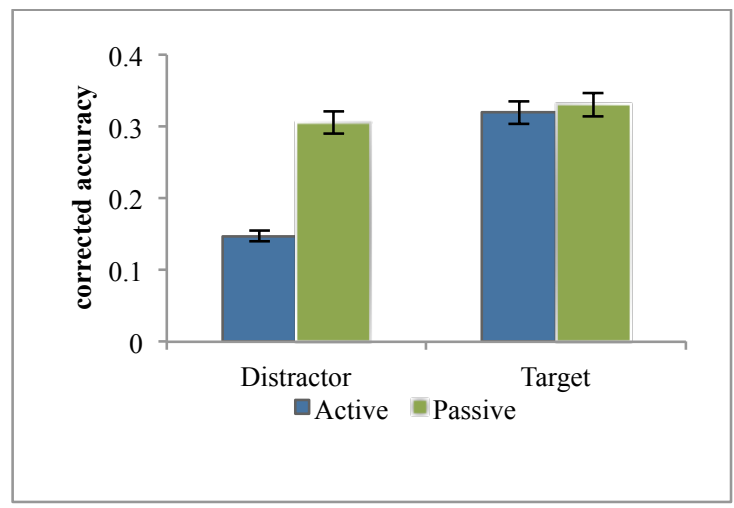

Figure 14. Mean accuracy values corrected by chance (0.0625) for full episodic memory during recall. 
For the 'What' test there was no two-way interaction to be reported and no measures was greater than chance.

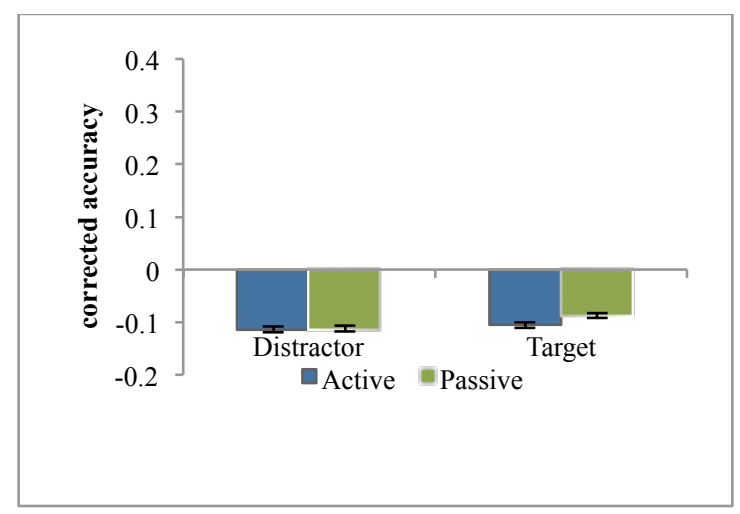

Figure 15. Mean accuracy values corrected by chance (0.1875) for non-episodic object identity recall.

Where (Non Episodic Spatial Recall)

Only the active target was remembered significantly better than chance $(p=.01)$. There were no other significant effects.

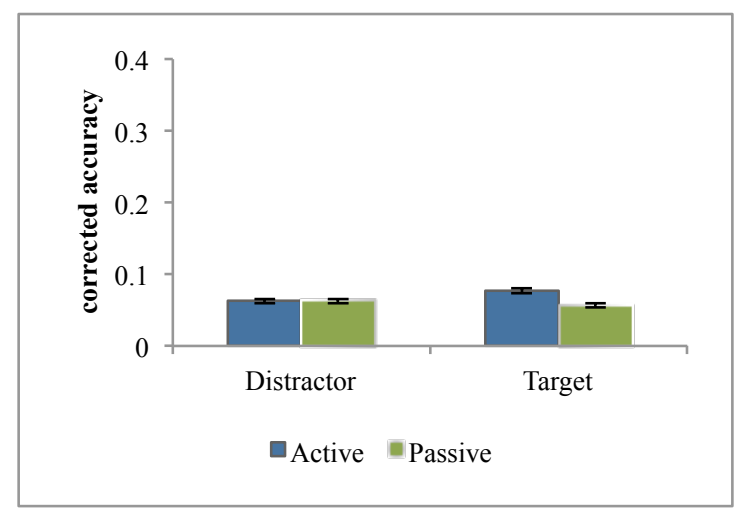

Figure 16. Mean accuracy values corrected by chance (0.0625) for non-episodic spatial recall. 
Only memory for passive targets was better than chance in the 'When' test $(p=.04)$ and there were no significant effects of any of the variables.

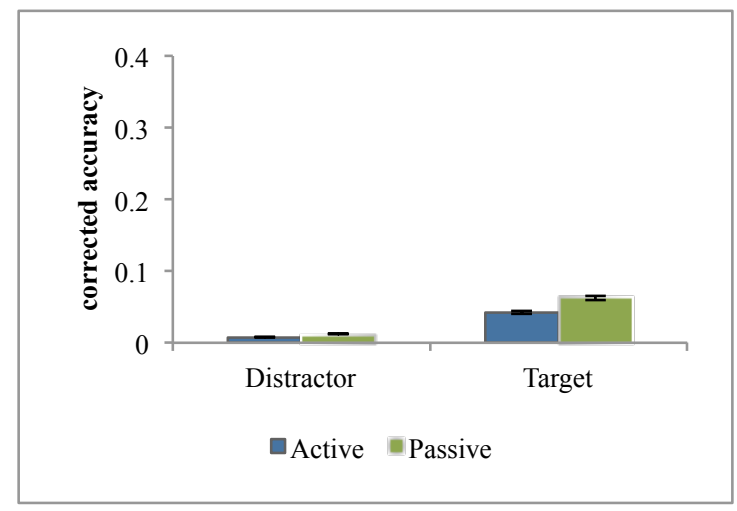

Figure 17. Mean accuracy values corrected by chance (0.1875) for non-episodic temporal recall.

\section{Discussion}

The new context involved a perceptually more complex 3D environment where retinotopic locations of these objects change with the viewpoint of a user-guided avatar. The level of involvement of the participant in the action was also expected to increase. The action now requires not only pointing to the object, but to also navigate the avatar until it reaches the selection place, a more exploratory action in line with the driving experiments reported by Plancher et al. (2007, 2012, see also Christou \& Bulthoff, 1999). All these changes were expected to increase the cognitive demands involved in both the selection of the target and the response to it. Despite all these changes, including different objects and set-ups, distractor suppression (rather than target enhancement) on episodic memory was replicated. This is an important validating result, as Second Life provides a radically different context for memory encoding and action involvement. 
Something worth discussing in this study are the differences between the active and passive conditions when the action takes place in a virtual environment like Second Life. In this set-up, participants witnessed a movie where actions were taking place. They actually saw the avatar acting on objects. We could have predicted that the passive condition in Second Life would resemble more the active one; however this was not the case. There was a significant reduction of distractor encoding on episodic memory on the active condition compared to the passive viewing of the action. These results strongly suggest that the execution of the action reduced the encoding of the distractor, and that this is not a mere effect emerging solely from increased perceptual attention.

The lack of distractor suppression in non-episodic memory of objects supports the role of inhibition and cognitive control on episodic encoding. However, as in most studies trying to compare 2D and 3D displays, the differences between the settings are too large to extract any conclusion about the nature of the encoding experience across displays (see also Cokburn, 2002). 


\section{GENERAL DISCUSSION}

In this study, we developed a WWW paradigm to study how the different objects participating in active selection are bound to space and time to form an episodic trace. The existing literature seems to favour that attended targets receive a processing boost that increases their encoding in memory in general (Attree, Brooks, Rose \& Andrews, 1996; James, Humphrey, Vilis, Corrie, Baddour, \& Goodale, 2001; Harman, Humphrey \& Goodale, 1999). But the evidence seems more scarce when it comes to episodic encoding. Indeed only few studies have looked into the impact of selective attention on episodic encoding, with rather mixed results. Some studies have suggested that actively selected targets receive a boost that increases their encoding in an episodic trace (Rosner et al, 2014; Uncapher \& Rugg, 2009; Uncapher \& Wagner, 2009). But several others have failed to find such evidence (Christou \& Bulthoff, 1999; Plancher et al, 2007). A common problem with these studies is that they do not separate between attended and unattended information, so it is unclear how much of the memory is attributed to relevant or irrelevant objects. Research from selective attention literature has suggested that, rather than boosting target processing, selection results in the inhibition of distractors (Houghton \& Tipper, 1994), more specifically if they were linked to an incompatible response (Houghton \& Marí-Beffa, 2005; Marí-Beffa, Houghton, Estevez \& Fuentes, 2000). More specifically, research on event files (Hommel, 1998) has theorised that this action-binding can be part of the episodic encoding, where even distractor information could get linked to specific responses during selection (the distractor-response binding phenomenon, Rothermund, Wentura \& De Hower, 2005; Moeller \& Frings, 2014); but how these event files are further bound to space and time in an episodic memory trace remains unclear. In our studies, for example, we have found that the episodic trace could be influenced by target-action binding, but we found no evidence for distractor-action binding. It is important to highlight, however, that our experiments were not designed to investigate 
response-distractor representations. Indeed, our selective attention tasks solely consist of the detection of a target. Any response bound to the distractor could be considered as a general "do-not-respond" tag like the one suggested in traditional episodic retrieval explanations of negative priming (Neill, Valdes \& Terry, 1992). But to further explore this issue, we could have defined a decision task (for example, "is the target blue or red") upon target selection in a way that distractors could be automatically bound to a particular response category. This procedure could be used to analyse, for example, how distractors linked to compatible and incompatible responses are represented in episodic traces. Nevertheless, the purpose of this initial set of studies was to validate the WWW task as a measure of episodic memory that can be used to study the impact of different selective attention states, with multiple potential extensions for further studies like the one mentioned here.

We presented three experiments demonstrating that actively selected objects do not receive a boost in episodic memory compared to passively selected ones. Our active condition involves goal-directed behaviour (invoking mostly prefrontal systems, e.g., Norman \& Shallice, 1996; Fuster, 1997) to a larger extent than the passive one (with more parietal involvement, Hutchinson, Uncapher \& Wagner, 2009), but this did not result in better memory, episodic or not, for those selected objects.

Our experiments strongly support that the action provokes the suppression of distractor encoding in episodic memory. This pattern has been consistently found every time we tested the successful retrieval of the three properties that have been traditionally associated to episodic memory encoding (Tulving, 1972): object, spatial and time. When at least one of these properties was forgotten (our non-episodic measures), distractor suppression was either absent or not consistent. This idea is compatible with the concept of episodic inhibition put forward by Racsmany and Conway (2006) in the context of directed forgetting tasks. They found that inhibited words would be still available when implicit tests are used (such as 
lexical decision) but would remain unavailable in explicit cue-recall tasks, which are likely to access episodic representations. This is clearly in contradiction with previous episodic accounts of negative priming based on the idea that distractors are episodically encoded (Neill, Valdes \& Terry, 1992). In our studies we have found that cue-recall task can retrieve information about objects which are often linked to space and memory features (our full episodic memory measure), but that sometimes are not. Just as Racsmany \& Conway (2006) would have predicted, distractor suppression was observed only in the full episodic measure. Whenever the code of space or time is lost from the object, distractor inhibition is not present. These results have strong consequences for applied research, especially in education, where the use of more active learning methods may not necessarily result in better memory, but possibly in concentration by reducing distraction (see ADHD, Nigg, 2001 for a review).

Our approach provides clear operational definition for what an episodic memory trace should contain, but it is less clear about what the non-episodic measures are. We know they represent estimations of explicit memory retrieval, but without more research it would be impossible to fully characterise their contents. Our results provide nevertheless some useful insights about the encoding of different properties outside the episodic memory trace. For example, across all experiments, the non-episodic retrieval of space and time is smaller in size than the episodic one, in many cases not even rising above chance levels. This pattern of results suggest that we better remember explicitly space and time when episodically represented.

Indeed selective encoding of targets against distractors was only observed with episodic memory in the active condition. In the experiments targets were better encoded episodically than distractors, but a key question is whether this is due to the action selectively enhancing memory for targets or selectively inhibiting the distractor. Importantly, we found no evidence of the action improving target encoding in the active condition, which was 
always similar to the passive one in the three experiments. Indeed, selection emerged as the distractor was systematically less remembered in the active condition compared to the passive one. These results are in accordance with those from negative priming studies where the main mechanism of active attentional selection is the inhibition of competing distractors (Houghton \& Tipper, 1994)

By separating target and distractor objects with the use of selective attention we can help explain some of the divergent results in current research, for instance that the level or type of involvement in the action could determine the information recalled in episodic memory. For example, our passive condition can be considered quite an active one in some other studies because our target objects are always salient in both modes. In Plancher et al (2012), for example, the passive condition allowed the participant to freely move attention across the scene. This free mode makes it impossible to understand where attention was being located through space and time. Some of the recalled items in this passive condition might have been attended while some others may not. In our studies the passive condition could be seen as a selective attention state with no behavioural goals associated to the selection of the target, while our active condition would be concerned with the explicit definition of a goal (or task) upon target information. The most passive measure in our design comes from the analysis of distractor objects in the passive mode, because attention is not withdrawn from the distractors in an explicit way. Participants here where instructed to focus on targets but distractors were never mentioned. This could have undoubtedly increase distractor processing during the passive condition, making it similar to the passive condition studied in navigation studies (Plancher et al., 2007, 2012). If it is true, then both target and distractor can be considered as targets, making episodic memory in our passive condition much higher than in the active one. This would explain why passengers in a driving simulation often report increased episodic memory in passive rather than in active contexts, suggesting that it could 
be due to the inclusion of distracting information under a passive mode. In any case, the pattern of results observed here would again be in clear contradiction with views suggesting target enhancement following selection.

\section{Second Life}

Virtual reality is popular because it enables researchers and clinicians to create situations that are close to daily life with experimental control (Plancher, Gyselinck, Nicolas \& Piolino 2010). Tipper, Howard and Jackson (1997) questioned what methods are most appropriate for understanding how the mammalian brain works. They explained that the current approach of cognitive psychology has been to develop highly controlled experimental procedures that have revealed properties, for example, of selective attention systems. These artificial situations however have not taken into account the ecological constraints that humans are faced with on a daily basis. Through the medium of Second Life an attempt was made to provide an alternative to $2 \mathrm{D}$ interface tests. To a large extent they replicated the results observed in the previous $2 \mathrm{D}$ experiments. This will prove that using more complex environments could be used as a base line to study more complex cognitive tasks that would allow good interaction techniques as being "natural" or at least "similar" to the physical world. The same pattern of results was observed across very different types of objects, across different paradigms and across a variety of contexts. These results are likely to apply to other procedures providing an ideal tool to measure inhibition and action control in episodic encoding.

To conclude, while traditional methods of selective attention have observed inhibitory processes, these have never been highlighted using episodic memory tests. On these grounds, the work achieved in this paper is original, and the findings that active selection of targets 
does not improve memory but removes distraction, can lead to practical applications in different areas such education.

\section{REFERENCES}

Attree, E. A., Brooks, B. M., Rose, F. D., \& Andrews, T. K. (1996). Memory processes and virtual environments: I can't remember what was there, but I can remember how I got there. Implications for people with disabilities. Proc. $1^{\text {st }}$ Euro. Conf. Disability, Virtual Reality \& Assoc. Tech., Maidenhead, UK.

Awh, E., Matsukura, M., \& Serences, J. (2003). Top-down control over biased competition during covert visual orienting. Journal of Experimental Psychology: Human Perception and Performance, 29, 52-63.

Babb, S. J., \& Johnson R. M. J. (2010). Object, spatial, and temporal memory: A behavioral analysis of visual scenes using a what, where, and when paradigm. Current psychology letters, 26(2).

Bainbridge, W. S. (2007). The scientific research potential of virtual worlds. Science, $317(5837), 472-6$.

Booth, K., B Fisher, B., Page, S., Ware, C., \& Widen, S. (2000). Wayfinding in a virtual environment. Graphics Interface.

Boronat, C. B., \& Logan, G. D. (1997). The role of attention in automatization: Does attention operate at encoding, or retrieval, or both? Memory \& Cognition, 25, 36-46

Bourke, P. (2008). Evaluating Second Life as a Tool for Collaborative Scientific Visualization. In: Computer Games and Allied Technology. Singapore. 
Brébion G, Smith MJ, Gorman JM, Amador X. (1996). Reality monitoring failure in schizophrenia: the role of selective attention. Schizophrenia Res, 22, 173-180.

Broadbent, D. E. (1982). Task combination and selective intake of information. Ada Psychologica, 50, 253-290.

Brooks, B.M., Atree, E.A., Rose, F.D., Clifford B. R., \& Leadbetter A. G. (1999). The Specificity of memory enhancement during interaction with a virtual environment. Memory, 7(1), 65-78.

Carassa, A., Geminiani, G., Morganti, F., \& Varotto, D. (2002). Active and passive spatial learning in a complex virtual environment: the effect of the efficient exploration. Cognitive Processing - International Quarterly of Cognitive Sciences, 3(4), 65-81.

Clayton, N.S, Bussey, T.J, Dickinson, A. (2003). Can animals recall the past and plan for the future? Nat Rev Neuroscience, 4(8), 685-91.

Clayton, N. S., \& Dickinson, A. (1999). Memory for the content of caches by scrub jays (Aphelocoma coerulescens). Journal of Experimental Psychology: Animal Behavior Processes, 25(1), 82.

Clayton, N. S., \& Russell, J. (2009). Looking for episodic memory in animals and young children: prospects for a new minimalism. Neuropsychologia, 47(11), 2330-40.

Cockburn, A., \& McKenzie, B. (2002). Evaluating the effectiveness of spatial memory in 2D and 3D physical and virtual environments. Proceedings of the SIGCHI conference on Human factors in computing systems Changing our world, changing ourselves - CHI '02, 203.

Conway MA. (2009). Episodic memories. Neuropsychologia. 47(11), 2305-13. 
Cheke, L. G., \& Clayton, N. S. (2013). Do different tests of episodic memory produce consistent results in human adults? Learning \& Memory, 20(9), 491-498.

Chrastil, E. R., \& Warren, W. H. (2012). Active and passive contributions to spatial learning. Psychonomic Bulletin \& Review, 19, 1-23.

Christou, C., \& Bulthoff, H. H. (1999). View dependence in scene recognition after active learning. Memory and Cognition, 27, 996-1007.

Eacott, M. J., Easton, A., \& Zinkivskay, A. (2005). Recollection in an episodic-like memory task in the rat. Learning \& memory, 12(3), 221-3.

Ferchiou, A., Schürhoff, F., Bulzacka, E., Mahbouli, M., Leboyer, M., \& Szöke, A. (2010). Source monitoring: general presentation and review of literature in schizophrenia. Encéphale, 36(4), 326-333.

Fuster J.M. (1997). The prefrontal cortex and the cognitive foundation of orderly action. In G.W. Mazur (Ed.), Twenty Year Commemoration to the Life of A.R. Luria, Semeneko Foundation, New York, pp. 45-60.

Gaunet, F., Vidal, V., Kemeny, A., \& Berthoz, A. (2001). Active, passive and snapshot exploration in a virtual environment: Influence on scene memory, reorientation and path memory. Cognitive Brain Research, 11, 409-420.

James, K. H., Humphrey, G. K., \& Goodale, M. A. (2001). Manipulating and recognizing virtual objects: Where the action is. Canadian Journal of Experimental Psychology, 55, 111-120.

Hampton, R. R., \& Schwartz, B. L. (2004). Episodic memory in nonhumans: What, and where, is when? Current Opinion in Neurobiology, 14, 192-197. 
Harman, K. L., Humphrey, G. K., \& Goodale, M. A. (1999). Active manual control of object views facilitates visual recognition. Current Biology, 9, 1315-1318.

Holland, S.M., \& Smulders, T. (2011). Do humans use episodic memory to solve a WhatWhere-When memory task? Animal Cognition, 14(1), 95-102.

Hommel, B. (1998). Event files: Evidence for automatic integration of stimulus-response episodes. Visual Cognition, 5, 183-216.

Hommel, B. (2004). Event files: feature binding in and across perception and action. Trends in Cognitive Sciences, 8(11), 494-500.

Hommel, B. (2010). Grounding attention in action control: The intentional control of selection. In B.J. Bruya (ed.), Effortless attention: A new perspective in the cognitive science of attention and action (pp. 121-140). Cambridge, MA: MIT Press.

Houghton, G., \& Marí-Beffa, P. (2005). Dissociating object-and response-based components of negative priming through effects of practice. Perception \& psychophysics, 67(8), $1423-1436$.

Houghton, G., \& Tipper, S. P. (1994). A model of inhibitory mechanisms in selective attention. In D. Dagenbach \& T. H. Carr (Eds.), Inhibitory processes in attention, memory, and language (pp. 53-112). San Diego: Academic Press.

Hutchinson, J.B, Uncapher, M.R. \& Wagner, A.D. (2009). Posterior parietal cortex and episodic retrieval: Convergent and divergent effects of attention and memory. Learning \& Memory. 16(6):343-356.

Jacoby, L. L. (1991). A process dissociation framework: Separating automatic from intentional uses of memory. Journal of Memory and Language, 30, 513-541. 
Kahneman, D., Treisman, A., \& Gibbs, B. J. (1992). The reviewing of object files Object specific integration of information. Cognitive Psychology, 24, 175-219.

Köhler, E., Keysers, C., Umilt, M.A., Fogassi, L., Gallese, V., \& Rizzolatti, G. (2002). Hearing sounds, understanding actions: action representation in mirror neurons. Science, 297, 846-848.

Kraeme, P. (2013). Do As We Do, Not As You Think: The Effect of Group Influence on Individual Choices in a Virtual Environment. Journal of Virtual Worlds Research, 6(1).

Logan, G. D., \& Etherton, J. L. (1994). What is learned during automatization? The role of attention in constructing an instance. Journal of Experimental Psychology: Learning, Memory, and Cognition, 20, 1022-1050.

Logan, G. D., Taylor, S. E., \& Etherton, J. L. (1999). Attention and automaticity: Toward a theoretical integration. Psychological Research, 62, 165-181.

Lekeu, F., Van der Linden, M., Moonen, G., \& Salmonet, E. (2002). Exploring the effect of action familiarity on SPTs recall performance in Alzheimer's disease. Journal of Clinical and Experimental, Neuropsychology, 24(8), 1057-1069.

MacLeod, C. M. (1991). Half a century of research on the Stroop effect: An integrated review. Psychological Bulletin, 109, 163-203.

Magnussen, S., \& Helstrup, T. (2007). Everyday Memory. Psychology Press.

Marí-Beffa, P., Houghton, G., Estévez, A. F., \& Fuentes, L. J. (2000). Word-based grouping affects the prime-task effect on semantic priming. Journal of Experimental Psychology: Human Perception and Performance, 26(2), 469. 
Mazza, V., Turatto, M., \& Caramazza, A. (2009). Attention selection, distractor suppression and N2pc. Cortex, 45, 879-890.

Mayr, S., \& Buchner. S. (2007). A, Negative priming as a memory phenomenon: A review of 20 years of negative priming research, Zeitschrift für Psychologie / Journal of Psychology, 215(1), 35 - 5.

Miller, G.A. (1956). The Magical Number Seven, Plus or Minus Two. The Psychological Review 63(2), 81-97.

Moeller, B., \& Frings, C. (2014). Attention meets binding: Only attended distractors are used for the retrieval of event files. Attention, Perception, \& Psychophysics, 76, 959-978.

Neill, W. T., Valdes, L. A., Terry, K. M., \& Gorfein, D. S. (1992). Persistence of negative priming: II. Evidence for episodic trace retrieval. Journal of Experimental Psychology: Learning, Memory, and Cognition, 18(5), 993.

Neill, W.T., \& Westberry, R.L. (1987). Selective attention and the suppression of cognitive noise. Journal of Experimental Psychology: Learning, Memory, and Cognition, 13, 327 334.

Nigg, J. T. (2001). Is ADHD a disinhibitory disorder?. Psychological bulletin, 127(5), 571.

Norman, D. A. \& Shallice, T. (1986). Attention to action: willed and automatic control of behaviour. In R. Davidson, G. Schwartz \& D. Shapiro (eds.) Consciousness and Self Regulation, Volume 4. NY: Plenum.

Perner, J. \& Ruffman, T. (1995). Episodic memory and autonoetic consciousness: Developmental evidence and a theory of childhood amnesia. Journal of Experimental Child Psychology, 59, 516-548. 
Péruch, P., Vercher, J-L. and Gauthier, G.M. (1995). Acquisition of spatial knowledge through visual exploration of simulated environments. Ecological Psychology, 7(1), 1-20.

Plancher, G., Gyselinck, V., Nicolas, S., \& Piolino, P. (2007). Influence of activity in episodic memory, use of virtual environment, In: S. Vosniadou, D. Kayser (Eds.), Proceedings of the Second European Cognitive Science Conference, Delphi. Greece.

Plancher, G., Nicolas, S., \& Piolino, P. (2008). Virtual reality as a tool for assessing episodic memory, In: $15^{\text {th }}$ ACM Symposium on Virtual Reality Software and Technology (VRST), Bordeaux.

Plancher, G., Gyselinck, V., Nicolas, S., \& Piolino, P. (2010). Age effect on components of episodic memory and feature binding: A virtual reality study. Neuropsychology, 24(3), $379-90$.

Plancher, G., Tirard, A., Gyselinck, V., Nicolas, S., \& Piolino P. (2012). Using virtual reality to characterize episodic memory profiles in amnestic mild cognitive impairment and Alzheimer's disease: influence of active and passive encoding. Neuropsychologia, 50(5), $592-602$.

Plancher, G., Barra, J., Orriols, E., \& Piolino, P. (2012). The influence of action on episodic memory: A virtual reality study. Quarterly Journal of Experimental Psychology, 1-15.

Racsmany, M., \& Conway, M.A. (2006). Episodic inhibition. Journal of Experimental Psychology: Learning, Memory \& Cognition, 32, 44-57.

Richter, F.R., \& Yeung, N. (2012). Memory and cognitive control in task switching. Psychology Science, 23(10), 1256-63. 
Roediger, H. L. (1973). Inhibition in recall from cueing with recall targets. Journal of Verbal Learning and Verbal Behavior, 12, 261-269

Rosner, T .M., D’Angelo, M. C., MacLellan, E., \& Milliken, B. (2014). Selective attention and recognition: Effects of congruency on episodic learning. Psychological Research.

Rothermund, K., Wentura, D., \& De Houwer, J. (2005). Retrieval of incidental stimulusresponse associations as a source of negative priming. Journal of Experimental Psychology: Learning, Memory, and Cognition, 31, 482-495.

Snodgrass, J.G., \& Vanderwart, M. J. A. (1980). Standardized set of 260 pictures: norms for name agreement, image agreement, familiarity, and visual complexity. Experimental Psychology: Human Learning, 6 (2), 174-215.

Tavanti, M., \& Lind, M. (2001). 2D vs 3D, Implications on Spatial Memory. In: IEEE Symposium on Information Visualization. 139.

Tipper, S. P. (1985). The negative priming effect: Inhibitory priming by ignored objects. Quarterly Journal of Experimental Psychology, 37A, 571-590.

Tipper, S. P., Driver, J., \& Weaver, B. (1991). Object-centred inhibition of return of visual attention. Quarterly Journal of Experimental Psychology, 43(2), 289-298.

Tipper, S.P. (2001). Does negative priming reflect inhibitory mechanisms? A review and integration of conflicting views. Quarterly Journal of Experimental Psychology: Human Experimental Psychology, 54A, 321-343.

Tong, F. H., Marlin, S. G., \& Frost, B. J. (1995). Cognitive map formation in a 3D visual virtual world. Poster presented at the IRIS/PRECARN workshop, Vancouver, BC. 
Toro-troconis, M., Kamel Boulos, M.N. (2009). 3D Virtual Worlds for Health and Healthcare. Journal of Virtual Worlds Research, 2(2).

Tulving, E. (1972). Episodic and semantic memory. In E. Tulving \& W. Donaldson (Eds.), Organization of memory (pp. 381-403). NewYork: Adademic Press.

Tulving, E. (2002). Episodic memory: From mind to brain. Annual Review of Psychology, 53, $1-25$.

Uncapher, M. R., \& Rugg, M. D. (2009). Selecting for memory? The influence of selective attention on the mnemonic binding of contextual information. Journal of Neuroscience. 29(25), 8270-9.

Van Asselen, M., Van der Lubbe, R. H. J., \& Postma, A. (2006). Are space and time automatically integrated in episodic memory, Memory. 14, 232 - 240.

Van Eynde, D. F., \& Spencer, R. W. (1988). Lecture versus experiential learning: Their different effects on long-term memory. Organizational Behavior Teaching Review, 12, $52-58$.

Wilson, P. N., \& Peruch, P. (2002). The influence of interactivity and attention on spatial learning in a desktop virtual environment. Current Psychology of Cognition, 21, 601-633.

Zimmer, H.D., Cohen, R.L., Guynn, M.J., Engelkamp, J., Kormi-Nouri, R., Foley, M.A. (2001). Memory for action: A distinct from episodic memory? (pp. 97-111). Oxford: Oxford University Press. 